\title{
Long-term follow-up of individuals with celiac disease: An evaluation of current practice guidelines
}

\author{
Jocelyn A Silvester PhD ${ }^{1}$, Mohsin Rashid FRCPC ${ }^{2}$
}

\begin{abstract}
JA Silvester, M Rashid. Long-term follow-up of individuals with celiac disease: An evaluation of current practice guidelines. Can J Gastroenterol 2007;21(9):557-564.
\end{abstract}

INTRODUCTION: Celiac disease can be treated by following a strict gluten-free diet for life. If properly followed, the diet resolves symptoms and nutritional deficiencies. It is generally recommended that individuals with celiac disease have careful long-term follow-up. However, it is not clear which elements of disease status evaluation, laboratory investigations and self-management support should be included in follow-up. OBJECTIVES: To examine the current practice guidelines and recommendations regarding follow-up of individuals with celiac disease.

METHODS: Guidelines issued by gastroenterological societies and associations, and recommendations by experts were retrieved using MEDLINE and other Internet search engines.

RESULTS: Practice guidelines were available from the American Gastroenterological Association; the North American Society for Pediatric Gastroenterology, Hepatology and Nutrition; the National Institutes of Health Consensus Development Conference 2004; the World Gastroenterology Organization; the British Society for Gastroenterology and the United Kingdom-based Primary Care Society for Gastroenterology. Most guidelines recommended a scheduled annual review and regular measurements of body mass index. The British Society for Gastroenterology recommended dietary review only at times of stress, while others recommended dietary review with a nutritionist. All associations recommended serial tissue transglutaminase antibody testing. The American Gastroenterological Association and the Primary Care Society for Gastroenterology recommended annual hemoglobin, ferritin and folate checks. One guideline recommended annual hemoglobin, electrolyte, calcium, albumin, ferritin, folate, fatsoluble vitamin, liver function test, parathyroid hormone and bone density measurements (approximately $\$ 400$ per patient).

CONCLUSIONS: The current practice guidelines regarding the follow-up of patients with celiac disease varied greatly in their recommendations and many were not evidence-based. Prospective studies are required to develop rational, cost-effective and risk-stratified guidelines for long-term follow-up of these patients.

Key Words: Celiac; Follow-up; Gluten-free diet

Celiac disease (gluten-sensitive enteropathy) is an autoimmune disorder that is estimated to affect $0.5 \%$ to $2.0 \%$ of the general population (1). It is treated by lifelong abstinence from ingestion of gluten, a cereal protein present in wheat, barley and rye. Traditionally, celiac disease has been considered to be a malabsorptive syndrome of childhood, presenting with abdominal pain, diarrhea, bloating and failure to thrive (2). As a result, it is not commonly diagnosed in adults, and

\section{Le suivi à long terme de personnes atteintes de la maladie coliaque : Une évaluation des lignes directrices courantes}

INTRODUCTION : Il est possible de traiter la maladie cœliaque au moyen d'un régime sans gluten strict pendant toute la vie. Bien respecté, le régime fait disparaître les symptômes et les carences nutritionnelles. Il est généralement recommandé d'assurer un suivi attentif et prolongé auprès des personnes atteintes d'une maladie cœliaque. Cependant, on ne sait pas quels éléments de l'évaluation de l'état de la maladie, des explorations de laboratoire et de l'autogestion devraient être inclus dans le suivi.

OBJECTIFS : Examiner les lignes directrices et recommandations courantes au sujet du suivi des personnes atteintes d'une maladie cœliaque.

MÉTHODOLOGIE : On a extrait les lignes directrices publiées par les sociétés et associations de gastroentérologie et les recommandations d'experts dans MEDLINE et d'autres moteurs de recherche par Internet.

RÉSULTATS : L'American Gastroenterological Association, la North American Society for Pediatric Gastroenterology, Hepatology and Nutrition, la conférence de développement de consensus 2004 des National Institutes of Health, l'Organisation mondiale de gastroentérologie, la British Society for Gastroenterology et la Primary Care Society for Gastroenterology du Royaume-Uni disposaient de lignes directrices. La plupart de ces lignes directrices recommandaient une analyse annuelle planifiée et des mesures régulières de l'indice de masse corporelle. La British Society for Gastroenterology recommandait une analyse alimentaire seulement en période de stress, tandis que les autres optaient pour une analyse alimentaire avec un nutritionniste. Toutes les associations recommandaient une détection sérielle des anticorps de la transglutaminase dans les tissus. L'American Gastroenterological Association et la Primary Care Society for Gastroenterology recommandaient une vérification annuelle de l'hémoglobine, des électrolytes, du calcium, de l'albumine, de la ferritine, des folates, des vitamines liposolubles, de la fonction hépatique, de l'hormone parathyroïde et de la densité osseuse (environ 400 \$ par patient).

CONCLUSIONS : Les recommandations contenues dans les lignes directrices courantes au sujet du suivi des patients atteints de la maladie cœliaque variaient considérablement, et bon nombre d'entre elles n'étaient pas fondées sur des faits probants. Des études prospectives sont nécessaires pour élaborer des lignes directrices rationnelles, rentables, et stratifiées selon le risque pour assurer le suivi à long terme de ces patients.

the true prevalence of the disease is underestimated. Recent studies have shown that celiac disease is much more common than previously realized. The prevalence of celiac disease in the United States has been found to be one in 133 people (3). In adults, celiac disease may present with nongastrointestinal symptoms such as iron deficiency anemia, decreased bone density, neurological symptoms or dermatitis herpetiformis (4). Many individuals at high risk are now screened for

${ }^{1}$ Dalhousie Medical School; ${ }^{2}$ Division of Gastroenterology and Nutrition, Department of Pediatrics, Dalhousie University, Halifax, Nova Scotia Correspondence: Dr Mohsin Rashid, Division of Gastroenterology, IWK Health Centre, Dalhousie University, 5850 University Avenue, Halifax,

Nova Scotia B3K 6R8. Telephone 902-470-8746, fax 902-470-7249, e-mail mohsin.rashid@iwk.nshealth.ca

Received for publication October 9, 2006. Accepted October 17, 2006 
celiac disease by serological testing with an anti-tissue transglutaminase antibody (tTG) or an endomysial antibody (5). With the advent of population screening, it was apparent that many individuals have 'silent' celiac disease, which is not manifested by intestinal symptoms, and that only the most symptomatic individuals were being identified, diagnosed and were prescribed a gluten-free diet (GFD) (6). Nevertheless, when asymptomatic individuals are identified by screening, those who adhere to a GFD do report a significant increase in their health-related quality of life in the short term (7) and compliance rates as high as their symptom-detected counterparts in the long term (8). This suggests that there is some health-related impact of so-called 'silent' celiac disease. Further evidence of the insidious burden of undiagnosed (and untreated) celiac disease was provided by a Finnish retrospective study (9) in which adults with elevated tTG and endomysial antibodies who had not received a diagnosis of celiac disease and who had consumed a gluten-containing diet had lower levels of educational and socioeconomic achievement than those who had been diagnosed with celiac disease in childhood and had adhered to a GFD.

Population studies have shown that celiac disease is associated with increased incidences of malignancy, particularly lymphoma, and autoimmune disorders, including type I diabetes and thyroid disease (2). Undiagnosed or poorly treated celiac disease has been associated with osteoporosis, iron deficiency anemia, depression and infertility, all of which are ameliorated, to some extent, by a GFD (10). These observations point to the importance of continued adherence to the GFD to ameliorate symptoms, avoid nutritional deficiencies and improve quality of life. Nevertheless, a significant proportion of patients do not adhere to a GFD. Those diagnosed in early childhood have consistently been shown to have the highest rates of compliance, with over $80 \%$ self-reporting strict adherence to a GFD later in childhood or in early adulthood $(11,12)$. The rate of adherence to a GFD decreases with age of diagnosis, and has been reported to be $56 \%$ to $83 \%$ in those diagnosed as adolescents and less than $50 \%$ in those diagnosed as adults (13). In one study (14) with a long-term follow-up period, $50 \%$ of patients diagnosed in childhood still consumed a strict GFD a mean of 28 years after diagnosis. In the same study, only $22 \%$ of individuals with celiac disease were followed by a gastroenterologist.

Much of the literature pertaining to celiac disease relates to diagnosis. The implications of treatment and follow-up have not been explored as thoroughly. This is reflected in the available practice guidelines for the diagnosis and management of celiac disease, many of which either do not mention or do not specify long-term follow-up of individuals with celiac disease. With limited access to a gastroenterologist, more and more patients are followed by their family physicians. Succinct and standardized practice guidelines would assist family physicians and gastroenterologists who follow individuals with celiac disease in providing care that is comprehensive and cost-effective. Because this disorder has such a high prevalence, long-term follow-up of patients with celiac disease could have a significant economic impact on the health care system.

The purpose of the present study was to examine the currently available practice guidelines for the follow-up of individuals with celiac disease and to evaluate the evidence for these recommendations.

\section{METHODS}

\section{Identification of practice guidelines}

Practice guidelines for the diagnosis, management and follow-up of celiac disease were retrieved using the search strings 'celiac disease practice guidelines' and 'coeliac disease practice guidelines' in PubMed and other Internet search engines. In PubMed, guidelines issued by the North American Society for Pediatric Gastroenterology, Hepatology and Nutrition (NASPGHAN) (15), the American Gastroenterological Association (AGA) technical review (10) and the June 2004 National Institutes of Health (NIH) Consensus Development Conference were found (16). Other search engines located the 2001 AGA position statement (17), as well as guidelines issued by the World Gastroenterology Organization (18), the British Society for Gastroenterology (BSG) (19) and the United Kingdom-based Primary Care Society for Gastroenterology (PCSG) (20). The World Gastroenterology Organization guidelines did not refer to the need for long-term follow-up of individuals diagnosed with celiac disease (18). Therefore, only the AGA, the PCSG, the BSG, the NIH and the NASPGHAN guidelines, each of which included at least some mention of long-term monitoring and follow-up, were considered for analysis. These were compared with a comprehensive model for the long-term management of celiac disease outlined by Pietzak (13).

\section{Cost of laboratory tests}

The reference values for the cost of laboratory tests were provided by the Department of Laboratory Medicine at the IWK Health Centre, Dalhousie University (Halifax, Nova Scotia). The amounts are expressed in Canadian dollars.

\section{RESULTS}

Most guidelines recommended a scheduled annual visit for individuals with celiac disease. An exception was the BSG, which recommended "review at times of stress, whether this be physical or emotional" (19), as well as review during pregnancy because of the increased risk of neural tube defects associated with folic acid deficiency. Table 1 compares the guidelines that recommended routine follow-up of individuals with celiac disease with respect to disease status evaluation, laboratory and radiological investigations, and selfmanagement support.

\section{Disease status evaluation}

The guidelines varied most widely in the degree in which the nature and content of the follow-up visit were detailed, and the specific investigations that were recommended $(13,15-20)$. Nevertheless, they all incorporated elements of disease status evaluation, investigations and self-management support (Table 1). It was generally agreed that disease status evaluation should include questions about symptoms, and measurements of weight, height and/or body mass index.

More detailed physical examination was specifically mentioned by the NASPGHAN (15) and by Pietzak (13), who advocated a detailed physical examination "aimed at screening for signs and symptoms of other autoimmune disorders, gastrointestinal cancers, and refractory sprue". There is little evidence provided to support this recommendation, which is different from the NIH consensus statement (16), which stated that "no established approach exists to screen for all complications of 
TABLE 1

Comparison of practice guidelines for long-term follow-up of individuals with celiac disease

\begin{tabular}{|c|c|c|c|c|c|c|}
\hline Category & $\begin{array}{c}\text { Pietzak, } \\
2005 \\
(13)\end{array}$ & $\begin{array}{c}\text { AGA, } \\
2001 \\
(17)\end{array}$ & $\begin{array}{c}\text { BSG, } \\
2002 \\
(19)\end{array}$ & $\begin{array}{c}\mathrm{NIH}, \\
2004 \\
(16)\end{array}$ & $\begin{array}{c}\text { NASPGHAN, } \\
2005 \\
(15)\end{array}$ & $\begin{array}{c}\text { PCSG, } \\
2006 \\
(20)\end{array}$ \\
\hline \multicolumn{7}{|l|}{ Disease status evaluation } \\
\hline $\begin{array}{l}\text { Assess symptoms } \\
\text { by interview }\end{array}$ & $\checkmark$ & $\checkmark$ & & $\checkmark$ & $\checkmark$ & $\checkmark$ \\
\hline $\begin{array}{l}\text { Measure weight, } \\
\text { height and BMI }\end{array}$ & $\checkmark$ & $\checkmark$ & & & $\checkmark$ & $\checkmark$ \\
\hline Physical examination & $n \checkmark$ & & & & $\checkmark$ & \\
\hline \multicolumn{7}{|l|}{ Laboratory investigations } \\
\hline $\begin{array}{l}\text { Serology } \\
\text { (tTG antibody) }\end{array}$ & $\checkmark$ & & & $\checkmark$ & $\checkmark$ & $\checkmark$ \\
\hline Hemoglobin or CBC & $\checkmark$ & $\checkmark$ & & & & $\checkmark$ \\
\hline Folate & $\checkmark$ & $\checkmark$ & & & & $\checkmark$ \\
\hline Ferritin & $\checkmark$ & $\checkmark$ & & & & $\checkmark$ \\
\hline Albumin & $\checkmark$ & & & & & $\checkmark$ \\
\hline Calcium & $\checkmark$ & $\checkmark$ & & & & $\checkmark$ \\
\hline Electrolytes & $\checkmark$ & & & & & \\
\hline Vitamin $\mathrm{B}_{12}$ & & & & & & $\checkmark$ \\
\hline Vitamins $A$ and $E$ & $\checkmark$ & & & & & \\
\hline Vitamin D & $\checkmark$ & & & & & $\checkmark$ \\
\hline Prothrombin time & $\checkmark$ & & & & & \\
\hline Alkaline phosphatase & e $\checkmark$ & $\checkmark$ & & & & $\checkmark$ \\
\hline Parathyroid hormone & e $\checkmark$ & & & & & \\
\hline Liver function tests & $\checkmark$ & & & & & \\
\hline \multicolumn{7}{|l|}{ Radiology investigations } \\
\hline DEXA scanning & $\checkmark$ & & & & & $\checkmark$ \\
\hline \multicolumn{7}{|c|}{ Self-management support } \\
\hline $\begin{array}{l}\text { Dietary review with } \\
\text { a dietician }\end{array}$ & $\checkmark$ & & & $\checkmark$ & $\checkmark$ & $\checkmark$ \\
\hline $\begin{array}{l}\text { Reinforce need for } \\
\text { adherence }\end{array}$ & & $\checkmark$ & & & $\checkmark$ & $\checkmark$ \\
\hline $\begin{array}{l}\text { Membership in } \\
\text { advocacy group }\end{array}$ & $\checkmark$ & $\checkmark$ & $\checkmark$ & $\checkmark$ & $\checkmark$ & $\checkmark$ \\
\hline
\end{tabular}

AGA American Gastroenterological Association; BMI Body mass index; BSG British Society for Gastroenterology; CBC Complete blood count; DEXA Dual energy x-ray absorptiometry; NASPGHAN North American Society for Pediatric Gastroenterology, Hepatology and Nutrition; NIH National Institutes of Health; PCSG Primary Care Society for Gastroenterology; tTG Tissue transglutaminase antibody

celiac disease, including lymphoma and adenocarcinoma of the small bowel".

\section{Laboratory investigations}

The BSG guidelines recommended "monitoring for complications" (19) as part of the long-term follow-up of individuals with celiac disease, but did not specify further what is intended. All the other guidelines referred to serological testing for antibodies (either tTG or others not specified) as part of the follow-up of individuals with celiac disease $(10,13,15-18,20)$. The strength of this recommendation varied from "routine" $(13,15,16,20)$ to "possibly useful" (10).

The BSG (19), the NIH (16) and the NASPGHAN (15) did not recommend any routine investigations other than serological screening. Pietzak (13) recommended a battery of tests, including a complete blood count and iron studies, as well as folate, vitamins A, D and E, electrolytes, albumin and total protein, liver function and prothrombin time measurements.
TABLE 2

Costs of laboratory tests

\begin{tabular}{lr}
\hline Laboratory investigation & Cost (\$) \\
\hline Serology (tissue transglutaminase antibody) & 28.00 \\
Complete blood count & 7.34 \\
Red blood cell folate & 18.80 \\
Ferritin & 18.80 \\
Albumin & 2.81 \\
Calcium & 3.86 \\
Electrolytes & 7.13 \\
Vitamin B 12 & 12.53 \\
Vitamin A & 27.65 \\
Vitamin D & 59.35 \\
Vitamin E & 27.55 \\
Prothrombin time & 4.52 \\
Alkaline phosphatase & 3.89 \\
Parathyroid hormone & 61.33 \\
Liver function (alanine aminotransferase, aspartate aminotransferase) & 7.78 \\
\hline
\end{tabular}

TABLE 3

Costs of recommended laboratory tests

\begin{tabular}{lc}
\hline Reference & Cost (\$) \\
\hline Pietzak (13) & 278.81 \\
Primary Care Society for Gastroenterology (20) & 155.38 \\
American Gastroenterological Association (17) & 52.69 \\
National Institutes of Health (16) & 28.00 \\
NASPGHAN (15) & 28.00
\end{tabular}

NASPGHAN North American Society for Pediatric Gastroenterology, Hepatology and Nutrition

Testing for serum $\mathrm{B}_{12}$ was not recommended by Pietzak (13) but was recommended by the PCSG (20). The AGA (17) and the PCSG (20) both recommended a subset of the tests recommended by Pietzak (13), including a complete blood count, iron studies, and folate and alkaline phosphatase levels. Only the PCSG (20) cited evidence for these recommendations within the guidelines; however, the evidence cited often referred to other guidelines in which specific evidence was not provided.

Radiology investigations

With respect to dual energy x-ray absorptiometry (DEXA) scanning to assess bone mineral density, Pietzak (13) recommended that it be repeated on an annual basis following diagnosis. The only guideline that mentioned DEXA scanning as part of routine follow-up was the PCSG (20), which recommended scanning at menopause for women, at 55 years of age for men and at any age following fragility fracture. These recommendations did not differ significantly from the guidelines for the general population (21).

Cost of recommended follow-up

The cost of each of the laboratory tests included in the recommendations is listed in Table 2 and the total cost of each of the prescribed panels is listed in Table 3 . The cost of DEXA scanning is approximately $\$ 200$. Because most guidelines do not recommend DEXA scanning during follow-up, the cost of this investigation is not included in the tables. 


\section{Disease status evaluation}

\section{DISCUSSION}

Disease status evaluation includes assessing the patient's success in refraining from ingesting gluten, as well as assessing whether the patient has symptoms or signs of any of the conditions or diseases that can complicate celiac disease. With respect to the first goal, there is evidence that interview is effective in assessing dietary compliance and correlates with small intestinal biopsy results (22). With respect to the second goal, malignancies and autoimmune disorders have been associated with celiac disease; however, the evidence to support routine screening for these conditions is equivocal.

Individuals with celiac disease have been shown to have a $30 \%$ increased risk of malignancy compared with the general population $(23,24)$. The malignancy most strongly associated with celiac disease is non-Hodgkin's lymphoma, of which enteropathy-associated T cell lymphoma is a subtype. Early studies estimated that people with celiac disease were at as high as 43 times the risk of the general population for developing non-Hodgkin's lymphoma (25), but subsequent population studies suggested that this was an overestimation $(24,26,27)$. These discrepancies may be explained by the relationship between the risk of malignancy and adherence to a GFD; however, the precise nature of this relationship is controversial (28). Askling et al (24) observed a trend toward normalization of the RR of lymphoma over time, which suggests that studies to date may have been confounded by the fact that, historically, celiac disease has been underdiagnosed, particularly among those with less severe symptoms.

Similar to malignancy, the degree of increased risk of developing autoimmune disease among individuals with celiac disease is unclear. The literature is dominated by studies showing the prevalence of celiac disease among those with an autoimmune disorder, but there is less information on the prevalence of autoimmune disorders among those with celiac disease. A study (29) of 335 individuals living in Finland who had been diagnosed with celiac disease a mean of 5.3 years previously showed that autoimmune disorders were significantly more prevalent in this group than in an age- and sex-matched control population of patients with other gastrointestinal disorders. The autoimmune disorders included type I diabetes mellitus (5.4\%; OR 3.8), autoimmune thyroiditis (5.4\%; OR 2.1), Sjögren syndrome (3.3\%; OR 11.3) and connective tissue disorders (7.2\%; OR 2.8). The risk of developing these disorders appears to be proportional to the age of diagnosis $(30,31)$, but the association with duration of gluten exposure is less clear $(31,32)$. Accordingly, for children diagnosed with celiac disease at two years of age or younger, the risk of developing an autoimmune disorder seems to be the same as that of the general population.

The temporal relationship between celiac disease and the onset of type I diabetes suggests that celiac disease precedes the onset of diabetes (33). Also, the prevalence of associated autoimmune disorders in the above studies was lower in the pediatric population $(23 \%)$ than in the adult population (30\%). Therefore, one may consider screening individuals with celiac disease for autoimmune disorders at diagnosis and during routine follow-up, particularly those who are diagnosed in adulthood. However, caution is warranted, because an increased prevalence may not be sufficient to justify a targeted screening program; there is no effective laboratory screening tool that can be used in clinical practice to detect the autoimmune diseases commonly associated with celiac disease in their early (preclinical) stages. Moreover, there is no established treatment to prevent the onset of these diseases, especially type I diabetes. Thus, it may be more helpful and effective to educate patients to be vigilant about the symptoms of these autoimmune disorders and to consult their health care provider early if they experience these symptoms. In follow-up visits, specific questions may be asked to elicit information about the presence of any clinical signs and symptoms of these disorders.

\section{Laboratory investigations}

The guidelines were most divergent with respect to which laboratory investigations should be performed routinely in the follow-up of individuals with celiac disease, especially in terms of screening for nutritional deficiencies. This is not surprising, given that there are relatively few studies that have considered the utility of follow-up laboratory screening for nutrient deficiencies. Instead, they have focused on identifying which deficiencies are detected at diagnosis, or in patients with untreated or poorly treated celiac disease. There are few studies addressing this issue in patients who are compliant with a GFD. Therefore, many of the recommendations were based on the findings of these studies or of studies comparing the nutritional content of the GFD to a regular diet. A major weakness of the latter studies is that they have focused on comparing gluten-free grains to regular (gluten-containing) grains and have not considered the diet in its entirety $(34,35)$. When total dietary intake, as recorded in a three-day food diary, was considered, although individuals with celiac disease had less than the recommended intake of fibre, calcium and iron, they consumed higher levels of calcium and fibre than the participants in the National Health and Nutrition Examination Survey (NHANES) (36). Although it is not clear whether supplements were included in the calculation of dietary intake, $91 \%$ of participants reported taking a vitamin or mineral supplement $(72 \%$ multivitamin or multimineral, $70 \%$ calcium and $15 \%$ iron). In a similar study, Italian teenagers with celiac disease following a GFD were found to consume less than the recommended intake of iron, calcium and fibre, but they consumed equivalent amounts to a control group without celiac disease who were on a regular diet (37).

tTG antibody serology: Serology has been shown to have poor specificity and sensitivity for detecting either adherence to a GFD or resolution of small intestinal villous lesions. In a study by Kaukinen et al (38), tTG antibody serology was negative in $59 \%$ of patients with Marsh III villous atrophy on a GFD, and the sensitivity of tTG antibody testing in detecting these lesions was only $41 \%$. Furthermore, at follow-up, Tursi et al (39) found that the proportion of patients with persistent lesions who were tTG antibody positive declined over the course of the study from $32 \%$ (11 of 34 patients) at six months to $6 \%$ (one of 17 patients) at 12 months to $\%$ (zero of six patients) at 18 months after inception of a GFD. Even in a multicentre European study (40) that concluded that tTG antibody testing was useful in monitoring dietary compliance, $60 \%$ of those who admitted to being noncompliant were tTG antibody negative. These data indicate that a negative tTG antibody test cannot be equated with either consumption of a strictly GFD or complete resolution of small intestinal lesions. Iron studies: Iron deficiency anemia is common at the time of diagnosis of celiac disease. It may be the presenting feature and 
usually resolves with a GFD. In a study of patients in whom iron deficiency anemia was the presenting feature of celiac disease, $77.8 \%$ recovered from their anemia after six months on a GFD without iron supplementation, and 50\% were no longer iron deficient after 12 months on a GFD (41). Those who did not recover from iron deficiency were premenopausal women who suffered menstrual blood loss. After one year on the GFD, $94.4 \%$ of patients had recovered from their anemia. One patient who had not recovered in that study was an elderly woman with long-standing anemia (20 years) and presumed bone marrow hypofunction. Similar results were obtained in a study (42) of children with celiac disease in India, $81 \%$ of whom were no longer anemic after six months on a GFD. In the adult study (41), clinical symptoms were inversely correlated with serum hemoglobin concentration, which was, in turn, inversely correlated with duodenal biopsy scores. Moreover, in a long-term follow-up study of 30 individuals with celiac disease who had adhered to a GFD for 10 years, none were iron deficient (43). Altogether, these results suggest that, in the absence of clinical symptoms or signs of anemia, the usefulness of iron studies as part of routine follow-up of patients with celiac disease is minimal.

Folate and vitamin $B_{12}$ measurements: In a long-term study (43) of 30 adults in Sweden with celiac disease, whose adherence to a GFD was confirmed by follow-up duodenal biopsy 10 years after diagnosis, $37 \%$ had low levels of vitamin $B_{6}$ and $20 \%$ had low levels of folate, despite consuming more than the Nordic nutrition recommendation of vitamin $\mathrm{B}_{6}$. All consumed more than the recommended amount of vitamin $B_{12}$, and none were vitamin $\mathrm{B}_{12}$-deficient. Notably, there was a poor correlation between dietary intake and plasma levels of micronutrients $(\mathrm{r}<0.18)$. These results are consistent with a study (44) of 37 individuals from Finland with celiac disease in which $79 \%$ of those individuals who had low red blood cell folate and $83 \%$ of those individuals who had low vitamin $B_{12}$ at diagnosis improved to normal levels within 12 months of treatment with a GFD. In a Scottish study (45) of 39 consecutive individuals diagnosed with celiac disease, those who were vitamin $B_{12}$ deficient at diagnosis had normal serum levels of the vitamin a mean of four months after commencing a GFD without vitamin supplementation. These results have been confirmed by an Italian study (46) in which folate and vitamin $\mathrm{B}_{12}$ deficiencies present at the time of diagnosis of celiac disease resolved with a GFD. These studies suggest that the majority of patients who are folate- or vitamin $B_{12}$-deficient recover within one year of starting a GFD without supplementation.

The degree of vitamin $B_{12}$ and folate deficiency among individuals with celiac disease was similar to those of the general population of the United States before widespread folic acid fortification. The increase in folate levels has been quite recent. Between 1988 and 1994, the prevalence of low red blood cell folate was $45.8 \%$, and it decreased to $7.3 \%$ between 1999 and 2000 (47).

Taken together, these data suggest that the level of folate and vitamin $B_{12}$ deficiency among individuals with celiac disease may not differ significantly from that of the general population, and that dietary supplementation is an efficient way to correct the deficiency among the general population. Gluten-free grain substitutes generally contain lower levels of these micronutrients than their gluten-containing counterparts, which tend to be fortified $(34,35)$. There is insufficient evidence to determine whether it is worthwhile to screen individuals with celiac disease for these deficiencies as part of routine follow-up care.

Calcium status: Many of the guidelines recommend that investigations to assess calcium status and/or bone mineral density be included as part of the routine follow-up. The BSG published a separate guideline (48) pertaining to osteoporosis in individuals with celiac disease, in which the recommendations did not differ significantly from those for the general population (21). As with other deficiencies, Pietzak (13) had the most comprehensive screening panel and recommended determination of serum calcium, vitamin D, alkaline phosphatase and parathyroid hormone levels, as well as annual DEXA scanning. The AGA (17) and the PCSG (20) both recommended assessment of serum alkaline phosphatase levels, while the BSG (19), NIH (16) and NASPGHAN (15) did not recommend any of these investigations. These recommendations are not supported by the evidence, which shows that for individuals with celiac disease, serum calcium, parathyroid hormone and alkaline phosphatase levels are not predictive of bone mineral density measured by DEXA scanning (49). Although DEXA scanning should be the preferred choice for assessing calcium and bone status in individuals with celiac disease, the studies evaluating its use were typically small and produced discordant results.

It has long been known that at the time of diagnosis, the prevalence of osteomalacia is greater among individuals with celiac disease than in the general population (50). However, in clinical practice, the detection rate of routine DEXA scanning at diagnosis does not justify the cost, and the recommendation to assess bone mineral density at diagnosis has been retracted by its initial proponents (51). The role of DEXA scanning after diagnosis is less clear, owing to the uncertain effect of a GFD on bone mineral density. Individuals diagnosed in childhood who adhere to a GFD have a higher rate of bone density increase than their peers (52) and a normal bone mineral density is achieved with long-term adherence to a GFD $(49,52-54)$. In adults who are diagnosed with celiac disease and subsequently adhere to a GFD, bone mineral density often increases during the first year when a GFD is consumed but does not necessarily revert to normal levels (55-57).

Another question regarding bone density and celiac disease is whether the measured changes in bone mineral density are associated with a clinically significant increased risk of fracture $(58,59)$. As well, decreased bone mineral density in individuals with celiac disease does not seem to be associated with disease severity or symptoms $(51,56,60)$. The reason for these observations may be that the mechanism of decreased bone mineral density in individuals with celiac disease is more complex and multifaceted than initially realized. Specifically, although decreased intestinal absorption of calcium and vitamin $\mathrm{D}$, and resultant secondary hyperparathyroidism, have been implicated as causative factors, there is also evidence that the process is mediated by associated proinflammatory cytokines and is independent of nutritional status (57).

In light of these findings, there is insufficient evidence to suggest whether the calcium levels should be evaluated as part of routine follow-up of all patients with celiac disease.

\section{Cost of recommended tests}

The cost of recommended follow-up laboratory tests ranges from $\$ 28.00$ to $\$ 278.81$. Given the paucity of evidence to 
support measurement of any of the laboratory parameters discussed above as part of routine follow-up of individuals with celiac disease, there is a risk that strict adherence to any of the guidelines that recommend laboratory investigations leads to unnecessary and expensive serial testing in these individuals. With the prevalence of celiac disease being approximately $1 \%$, this would be an enormous cost to the health care system.

\section{Self-management support}

The purpose of follow-up: The purpose of follow-up, as outlined in the practice guidelines $(13,15,16,19,20)$, is to monitor for complications and to assess compliance. The need for compliance is particularly important in the context of celiac disease, because there is no pharmacological treatment involved; therefore, the onus is on the individual to self-manage their condition by being vigilant about their adherence to a GFD. Arguably, the health care team has a duty to empower the individual to self-manage their chronic disease, both to optimize health, and to minimize morbidity and mortality (61). Given that many complications are associated with continued consumption of gluten, it is prudent to consider the experience of individuals with celiac disease, the challenges they face and whether they feel sufficiently able to manage their own condition beyond their health care providers' offices.

Dietary review with a dietician: Pietzak (13), the NIH (16), the PCSG (20) and the NASPGHAN (15) all recommended that dietary review with a dietician should be part of long-term follow-up. Although the logic behind this seems clear, the evidence for the effectiveness of this measure in improving adherence to a GFD is limited. Nevertheless, there is some evidence that compliance is related to knowledge of celiac disease (62). Interestingly, when individuals with celiac disease are surveyed, a significant number report that they do not find the advice that they receive from a dietician to be very helpful $(12,63,64)$, and less than $13 \%$ identify better dietary counselling as something that would improve their quality of life $(12,64)$.

Reinforcement of the continuing need for adherence to a GFD: The majority of the guidelines $(13,15,16,19,20)$ recommended reinforcing the continuing need for compliance with the GFD at follow-up visits. When individuals with celiac disease were surveyed, over $90 \%$ reported that they attempt to adhere to the GFD most of the time $(12,64,65)$, which suggests that most individuals with celiac disease appreciate the need to comply with the GFD. Given that even when compliance was assessed as 'good' (no gluten-containing food) by a trained interviewer, $9.4 \%$ of these individuals had intestinal damage (22). It is likely that lack of adherence to the GFD may not stem from misinformation or lack of knowledge about the need to adhere to the diet, but from the practical difficulties associated with adhering to such a diet.

Uncertainty about the gluten content of products is common and consistent with self-reports that gluten ingestion is usually unintentional $(12,64,66-68)$. The inadvertent ingestion of gluten can be due to inaccurate product labelling (69). In a study (14) of 50 adults who had been diagnosed with celiac disease as children in Ireland a mean of 28 years previously, $86 \%$ cited the inconvenience of adhering to a GFD as the primary reason for intentional consumption of gluten; avoidance of symptoms was the main reason individuals adhered to the diet. This 'inconvenience' reflects the social and practical burdens of adhering to a GFD (70). In two large surveys of children (12) and adults (64) with celiac disease, better product labelling and more gluten-free foods in the supermarket and restaurants were identified as changes that would most improve their quality of life.

These practical and social burdens associated with the GFD have been linked to the decreased quality of life reported by individuals with celiac disease who had been following a GFD for more than one year compared with individuals who did not have celiac disease $(71,72)$. In one study $(73)$, individuals with celiac disease who did not adhere to a GFD reported a higher quality of life than those who did, suggesting that the effect may be related to the impact of adhering to the diet and not to the disease itself. The importance of considering and treating psychological factors was suggested by a small, six-month intervention in which a group of individuals, recently diagnosed with celiac disease, were provided with psychological support in the form of stress management seminars and discussions to identify problems related to celiac disease, the GFD and daily life. These individuals were significantly more compliant than those who did not receive this support (74).

Adherence to a GFD affects many aspects of an individual's functioning. Most importantly, from the health care provider's perspective, it must be recognized that compliance with a GFD often requires considerable lifestyle modifications, impacts on relationships with friends, family and colleagues, and is dependent on environmental factors.

Referral to a local advocacy group: Members of celiac associations consistently report better compliance with the GFD than studies of the entire celiac population $(12,64,66,75)$. Whether this represents a selection bias or a truly beneficial effect of membership is uncertain. In a British survey (67) of individuals with celiac disease a mean of 5.4 years after diagnosis, $50 \%$ of respondents were unsure as to whether they had eliminated gluten from their diet, even though $82 \%$ were members of Coeliac UK and would, therefore, be expected to be reasonably well informed. This suggests that while membership in an advocacy group may be helpful, this does not fully ensure that individuals with celiac disease can confidently adhere to a GFD.

Other potential benefits of membership in an advocacy group include the psychological support provided by others who are struggling with the same condition, as well as continuous provision of updated information regarding the disease, the diet and gluten-free products. This is important, because celiac disease has been identified as socially isolating (70), and the marketplace for gluten-free products, as well as the gluten content of existing products, is constantly changing.

\section{What do individuals with celiac disease say?}

There is a dearth of literature pertaining to the preferred form of follow-up for individuals with celiac disease. When individuals with celiac disease in the United Kingdom were surveyed about their preference, a mean of 5.4 years after diagnosis, $77 \%$ responded that they found an annual symptom review and blood test to be useful, and $60 \%$ found the opportunity for dietary review useful (67). Only 9\% responded that general reassurance was not useful. When this same group was asked about which of the five forms of follow-up they preferred, no follow-up was the least preferred option, despite the fact that $40 \%$ of respondents reported that they were not presently receiving active follow-up for their celiac disease. Seeing a dietician with a doctor available was the preferred option, and 
the preference for this option over seeing a hospital-based physician was statistically significant.

This raises the question not only of which forms of follow-up should be offered, but also who should be responsible for providing follow-up care. The need for long-term hospital follow-up of individuals with celiac disease has been defended as necessary because of the increased frequency of associated conditions, such as malignancy, autoimmune disease and bone disease, which are typically identified and managed by physicians (17). However, the PCSG guidelines specify that it is the role of the general practitioner to ensure that "the patient is reviewed annually with or without the input of the gastroenterologist and/or dietitian, depending on the needs of the patient" (20), the NIH guidelines recommend "continuous long-term follow-up by a multidisciplinary team" (16) and the NASPGHAN makes no specific recommendation because of inadequate evidence (15).

No matter who follows individuals with celiac disease, the medical management of the disease is only a small aspect of the management, and follow-up should include developing coping strategies and improving functioning, not simply measuring laboratory parameters. Rather than condemn those individuals with celiac disease who struggle with the complete elimination of gluten from their diet, health care professionals must adopt a more enlightened view that looks beyond noncompliance as

\section{REFERENCES}

1. Rewers M. Epidemiology of celiac disease: What are the prevalence, incidence, and progression of celiac disease? Gastroenterology 2005;128:S47-51.

2. Green PH, Jabri B. Coeliac Disease. Lancet 2003;362:383-91.

3. Fasano A, Berti I, Gerarduzzi T, et al. Prevalence of celiac disease in at-risk and not-at-risk groups in the United States: A large multicenter study. Arch Intern Med 2003;163:286-92.

4. Rampertab SD, Pooran N, Brar P, Singh P, Green PH. Trends in the presentation of celiac disease. Am J Med 2006;119:355.e9-14.

5. Green PH. The many faces of celiac disease: Clinical presentation of celiac disease in the adult population. Gastroenterology 2005;128:S74-8.

6. Catassi C, Ratsch IM, Fabiani E, et al. Coeliac disease in the year 2000: Exploring the iceberg. Lancet 1994;343:200-3.

7. Mustalahti K, Lohiniemi S, Collin P, Vuolteenaho N, Laippala P, Maki M. Gluten-free diet and quality of life in patients with screen-detected celiac disease. Eff Clin Pract 2002;5:105-13.

8. Viljamaa M, Collin P, Huhtala H, Sievnen H, Maki M, Kaukinen K. Is coeliac disease screening in risk groups justified? A fourteen-year follow-up with special focus on compliance and quality of life. Aliment Pharmacol Ther 2005;22:317-24.

9. Verkasalo MA, Raitakari OT, Viikari J, Marniemi J, Savilahti E. Undiagnosed silent coeliac disease: A risk for underachievement? Scand J Gastroenterol 2005;40:1407-12.

10. Ciclitira PJ, King AL, Fraser JS. AGA technical review on celiac sprue. American Gastroenterological Association. Gastroenterology 2001;120:1526-40. (Erratum in 2001;121:234).

11. Hogberg L, Grodzinsky E, Stenhammar L. Better dietary compliance in patients with coeliac disease diagnosed in early childhood. Scand J Gastroenterol 2003;38:751-4.

12. Rashid M, Cranney A, Zarkadas M, et al. Celiac disease: Evaluation of the diagnosis and dietary compliance in Canadian children. Pediatrics 2005;116:e754-9.

13. Pietzak MM. Follow-up of patients with celiac disease: Achieving compliance with treatment. Gastroenterology 2005;128:S135-41.

14. O'Leary C, Wieneke P, Healy M, Cronin C, O'Regan P, Shanahan F. Celiac disease and the transition from childhood to adulthood: A 28-year follow-up. Am J Gastroenterol 2004;99:2437-41.

15. Hill ID, Dirks MH, Liptak GS, et al. North American Society for Pediatric Gastroenterology, Hepatology and Nutrition. Guideline for the diagnosis and treatment of celiac disease in children: Recommendations of the North American Society for Pediatric Gastroenterology, Hepatology and Nutrition. J Pediatr Gastroenterol Nutr 2005;40:1-19. an act of individual failure or defiance to consider the social factors that render compliance difficult, even for the wellinformed and highly motivated patient.

\section{CONCLUSION}

Practice guidelines regarding the follow-up of individuals with celiac disease varied greatly. Many recommendations were not evidence-based. Furthermore, these guidelines focussed on measuring compliance and were not sufficiently comprehensive to incorporate an evaluation of the daily challenges faced by those who attempt to adhere to a GFD. It has not been determined to what extent the guidelines for long-term follow-up of individuals with celiac disease are reflected in practice. The investigations recommended in some of the current practice guidelines, if applied to all patients, irrespective of their disease status, are unnecessary and would incur significant costs to the health care system. Prospective studies are required to develop evidence-based and cost-effective strategies for the long-term follow-up of individuals with celiac disease.

Dr Rashid is a member of the Professional Advisory Board, Canadian Celiac Association.
16. National Institutes of Health Consensus Development Conference Statement on Celiac Disease, June 28-30, 2004. Gastroenterology 2005;128:S1-9.

17. American Gastroenterological Association. American Gastroenterological Association medical position statement: Celiac sprue. Gastroenterology 2001;120:1522-5.

18. World Gastroenterology Organisation. WGO practice guideline: Celiac disease. < http://www.worldgastroenterology.org/globalguidelines /guide13/guideline13.htm> (Version current at September 20, 2006).

19. British Society for Gastroenterology. Guidelines for the management of patients with coeliac disease. <http://www.bsg.org.uk/pdf_word_docs/coeliac.doc> (Version current at September 20, 2006).

20. Primary Care Society for Gastroenterology. The management of adults with coeliac disease in primary care.

$<$ http://www.pcsg.org.uk> (Version current at September 20, 2006).

21. Royal College of Physicians and Bone and Tooth Society of Great Britain. Osteoporosis: Clinical guidelines for prevention and treatment. Working Party Report. < http://www.rcplondon.ac.uk/pubs/ wp/wp_osteo_update.htm> (Version current at September 20, 2006).

22. Ciacci C, Cirillo M, Cavallaro R, Mazzacca G. Long-term follow-up of celiac adults on gluten-free diet: Prevalence and correlates of intestinal damage. Digestion 2002;66:178-85.

23. West J, Logan RF, Smith CJ, Hubbard RB, Card TR. Malignancy and mortality in people with coeliac disease: Population based cohort study. BMJ 2004;329:716-9.

24. Askling J, Linet M, Gridley G, Halstensen TS, Ekstrom K, Ekbom A Cancer incidence in a population-based cohort of individuals hospitalized with celiac disease or dermatitis herpetiformis. Gastroenterology 2002;123:1428-35.

25. Holmes GK, Prior P, Lane MR, Pope D, Allan RN. Malignancy in coeliac disease - effect of a gluten free diet. Gut 1989;30:333-8.

26. Green PH, Fleischauer AT, Bhagat G, Goyal R, Jabri B, Neugut AI. Risk of malignancy in patients with celiac disease. Am J Med 2003;115:191-5.

27. Viljamaa M, Kaukinen K, Pukkala E, Hervonen K, Reunala T, Collin P. Malignancies and mortality in patients with coeliac disease and dermatitis herpetiformis: 30 -year population-based study. Dig Liver Dis 2006;38:374-80.

28. Loftus CG, Loftus EV Jr. Cancer risk in celiac disease. Gastroenterology 2002;123:1726-9.

29. Collin P, Reunala T, Pukkala E, Laippala P, Keyrilainen O, Pasternack A. Coeliac disease - associated disorders and survival. Gut 1994;35:1215-8. 
30. Ventura A, Magazzu G, Greco L. Duration of exposure to gluten and risk for autoimmune disorders in patients with celiac disease. SIGEP Study Group for Autoimmune Disorders in Celiac Disease. Gastroenterology 1999;117:297-303.

31. Sategna Guidetti C, Solerio E, Scaglione N, Aimo G, Mengozzi G. Duration of gluten exposure in adult coeliac disease does not correlate with the risk for autoimmune disorders. Gut 2001;49:502-5.

32. Viljamaa M, Kaukinen K, Huhtala H, Kyronpalo S, Rasmussen M, Collin P. Coeliac disease, autoimmune diseases and gluten exposure. Scand J Gastroenterol 2005;40:437-43.

33. Peretti N, Bienvenu F, Bouvet $\mathrm{C}$, et al. The temporal relationship between the onset of type I diabetes and celiac disease: A study based on immunoglobulin a antitransglutaminase screening. Pediatrics 2004;113:e418-22.

34. Thompson T. Thiamin, riboflavin, and niacin contents of the gluten-free diet: Is there cause for concern? J Am Diet Assoc 1999;99:858-62.

35. Thompson T. Folate, iron, and dietary fiber contents of the gluten-free diet. J Am Diet Assoc 2000;100:1389-96.

36. Thompson T, Dennis M, Higgins LA, Lee AR, Sharrett MK. Gluten-free diet survey: Are Americans with coeliac disease consuming recommended amounts of fibre, iron, calcium and grain foods? J Hum Nutr Diet 2005;18:163-9.

37. Mariani P, Viti MG, Montouri M, et al. The gluten-free diet: A nutritional risk factor for adolescents with celiac disease? J Pediatr Gastroenterol Nutr 1998;27:519-23.

38. Kaukinen K, Sulkanen S, Maki M, Collin P. IgA-class transglutaminase antibodies in evaluating the efficacy of gluten-free diet in coeliac disease. Eur J Gastroenterol Hepatol 2002;14:311-5.

39. Tursi A, Brandimarte G, Giorgetti G. Lack of usefulness of anti-transglutaminase antibodies in assessing histologic recovery after gluten-free diet in celiac disease. J Clin Gastroenterol 2003;37:387-91.

40. Fabiani E, Catassi C; International Working Group. The serum IgA class anti-tissue transglutaminase antibodies in the diagnosis and follow up of coeliac disease. Results of an international multicentre study. International Working Group on Eu-tTG. Eur J Gastroenterol Hepatol 2001;13:659-65.

41. Annibale B, Severi C, Chistolini A, et al. Efficacy of gluten-free diet alone on recovery from iron-deficiency anemia in adult celiac patients. Am J Gastroenterol 2001;96:132-7.

42. Patwari AK, Anand VK, Kapur G, Narayan S. Clinical and nutritional profile of children with celiac disease. Indian Pediatr 2003;40:337-42.

43. Hallert C, Grant C, Grehn S, et al. Evidence of poor vitamin status in coeliac patients on a gluten-free diet for 10 years. Aliment Pharmacol Ther 2002;16:1333-9.

44. Kemppainen TA, Kosma VM, Janatuinen EK, Julkunen RJ, Pikkarainen PH, Uusitupa MI. Nutritional status of newly diagnosed celiac disease patients before and after the institution of a celiac disease diet - association with the grade of mucosal villous atrophy. Am J Clin Nutr 1998;67:482-7.

45. Dahele A, Ghosh S. Vitamin $B_{12}$ deficiency in untreated celiac disease. Am J Gastroenterol 2001;96:745-50

46. Saibeni S, Lecchi A, Meucci G, et al. Prevalence of hyperhomocysteinemia in adult gluten-sensitive enteropathy at diagnosis: Role of $\mathrm{B}_{12}$, folate, and genetics. Clin Gastroenterol Hepatol 2005;3:574-80.

47. Ganji V, Kafai MR. Trends in serum folate, RBC folate, and circulating total homocysteine concentrations in the United States: Analysis of data from National Health and Nutrition Examination Surveys, 1988-1994, 1999-2000, and 2001-2002. J Nutr 2006;136:153-8.

48. Scott EM, Gaywood I, Scott BB. Guidelines for osteoporosis in coeliac disease and inflammatory bowel disease. British Society of Gastroenterology. Gut 2000;46:1-8.

49. Kavak U, Yuce A, Kocak N, et al. Bone mineral density in children with untreated and treated celiac disease. J Pediatr Gastroenterol Nutr 2003;37:434-6.

50. Salvesen HA, Boe J. Osteomalacia in sprue. Acta Med Scand 1953;146:290-9.
51. Lewis NR, Scott BB. Should patients with coeliac disease have their bone mineral density measured? Eur J Gastroenterol Hepatol 2005; $17: 1065-70$

52. Mora S, Barera G, Ricotti A, Weber G, Bianchi C, Chiumello G. Reversal of low bone density with a gluten-free diet in children and adolescents with celiac disease. Am J Clin Nutr 1998;67:477-81.

53. Szathmari M, Tulassay T, Arato A, Bodanszky H, Szabo A, Tulassay Z. Bone mineral content and density in asymptomatic children with coeliac disease on a gluten-free diet. Eur J Gastroenterol Hepatol 2001;13:419-24.

54. Mora S, Barera G, Beccio S, et al. Bone density and bone metabolism are normal after long-term gluten-free diet in young celiac patients. Am J Gastroenterol 1999;94:398-403.

55. Kemppainen T, Kroger H, Janatuinen E, et al. Bone recovery after a gluten-free diet: A 5-year follow-up study. Bone 1999;25:355-60.

56. Corazza GR, Di Sario A, Cecchetti L, et al. Influence of pattern of clinical presentation and of gluten-free diet on bone mass and metabolism in adult celiac disease. Bone 1996;18:525-30.

57. Corazza GR, Di Stefano M, Maurino E, Bai JC. Bones in coeliac disease: Diagnosis and treatment. Best Pract Res Clin Gastroenterol 2005; 19:453-65.

58. Vasquez H, Mazure R, Gonzalez D, et al. Risk of fractures in celiac disease patients: A cross-sectional, case-control study. Am J Gastroenterol 2000;95:183-9.

59. Fickling WE, McFarlane XA, Bhalla AK, Robertson DA. The clinical impact of metabolic bone disease in coeliac disease. Postgrad Med J 2001;77:33-6.

60. Molteni N, Caraceni MP, Bardella MT, Ortolani S, Gandolini GG, Bianchi P. Bone mineral density in adult celiac patients and the effect of gluten-free diet from childhood. Am J Gastroenterol 1990;85:51-3.

61. Redman BK. The ethics of self-management preparation for chronic illness. Nurs Ethics 2005;12:360-9.

62. Ljungman G, Myrdal U. Compliance in teenagers with coeliac disease - a Swedish follow-up study. Acta Paediatr 1993;82:235-8

63. Lee A, Newman JM. Celiac diet: Its impact on quality of life. J Am Diet Assoc 2003;103:1533-5.

64. Zarkadas M, Cranney A, Case S, et al. The impact of a gluten-free diet on adults with coeliac disease: Results of a national survey. J Hum Nutr Diet 2006;19:41-9.

65. Green PHR, Stavropoulos SN, Panagi SG, et al. Characteristics of adult celiac disease in the USA: Results of a national survey. Am J Gastroenterol 2001;96:126-31.

66. Lamontagne P, West GE, Galibois I. Quebecers with celiac disease: Analysis of dietary problems. Can J Diet Pract Res 2001;62:175-81.

67. Bebb JR, Lawson A, Knight T, Long RG. Long-term follow-up of coeliac disease - what do coeliac patients want? Aliment Pharmacol Ther 2006;23:827-31.

68. Cranney A, Zarkadas M, Graham ID, Switzer C. The Canadian celiac health survey - the Ottawa chapter pilot. BMC Gastroenterol 2003;3:8.

69. Ciacci C, Mazzaca G. Unintentional gluten ingestion in celiac patients. Gastroenterology 1998;115:243.

70. Sverker A, Hensing G, Hallert C. 'Controlled by food' - lived experiences of coeliac disease. J Hum Nutr Diet 2005;18:171-80.

71. Hallert C, Granno C, Grant C, et al. Quality of life of adult coeliac patients treated for 10 years. Scand J Gastroenterol 1998;33:933-8

72. Hallert C, Lohiniemi S. Quality of life of celiac patients living on a gluten-free diet. Nutrition 1999;15:795-7.

73. Roos S, Karner A, Hallert C. Psychological well-being of adult coeliac patients treated for 10 years. Dig Liver Dis 2006;38:177-80.

74. Addolorato G, De Lorenzi G, Abenavoli L, Leggio L, Capristo E, Gasbarrini G. Psychological support counselling improves gluten-free diet compliance in coeliac patients with affective disorders. Aliment Pharmacol Ther 2004;20:777-82.

75. Ciacci C, D'Agate C, De Rosa A, et al. Self-rated quality of life in celiac disease. Dig Dis Sci 2003;48:2216-20. 


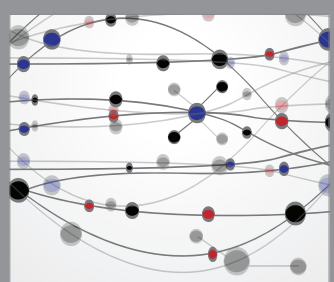

The Scientific World Journal
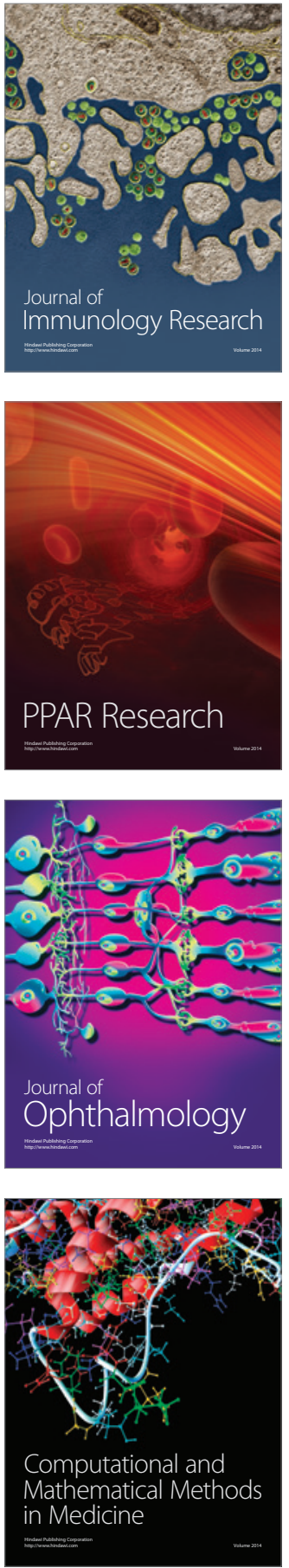

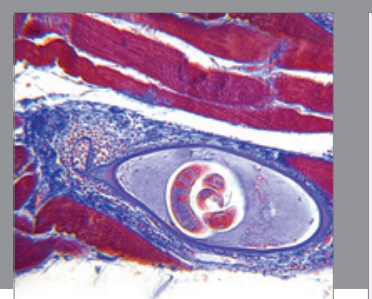

Gastroenterology Research and Practice

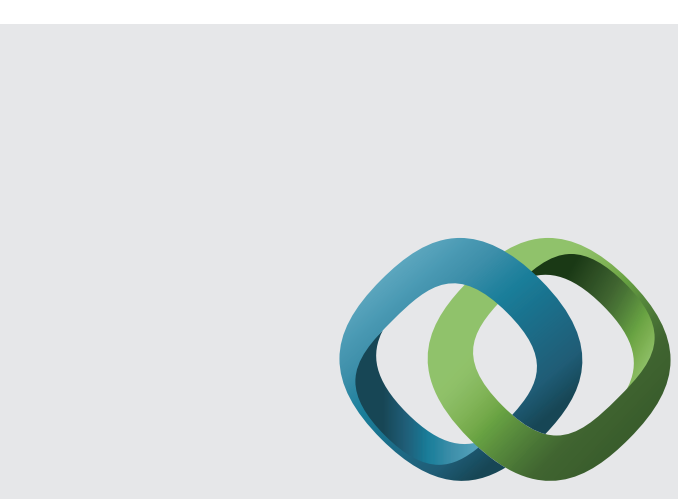

\section{Hindawi}

Submit your manuscripts at

http://www.hindawi.com
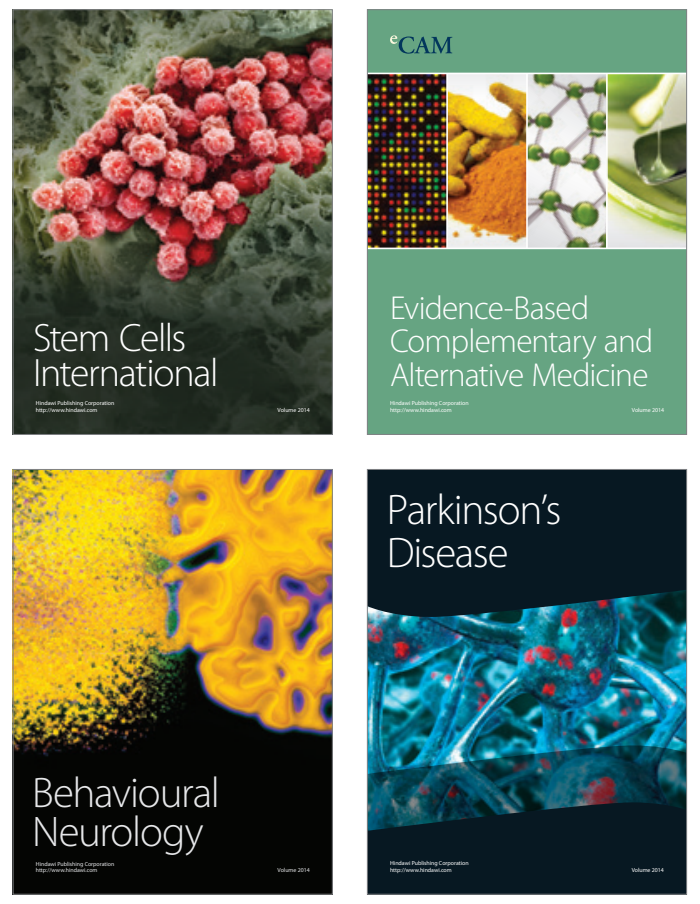
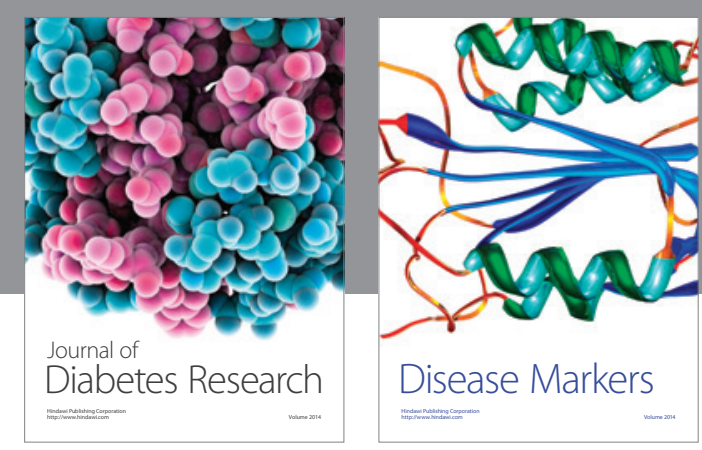

Disease Markers
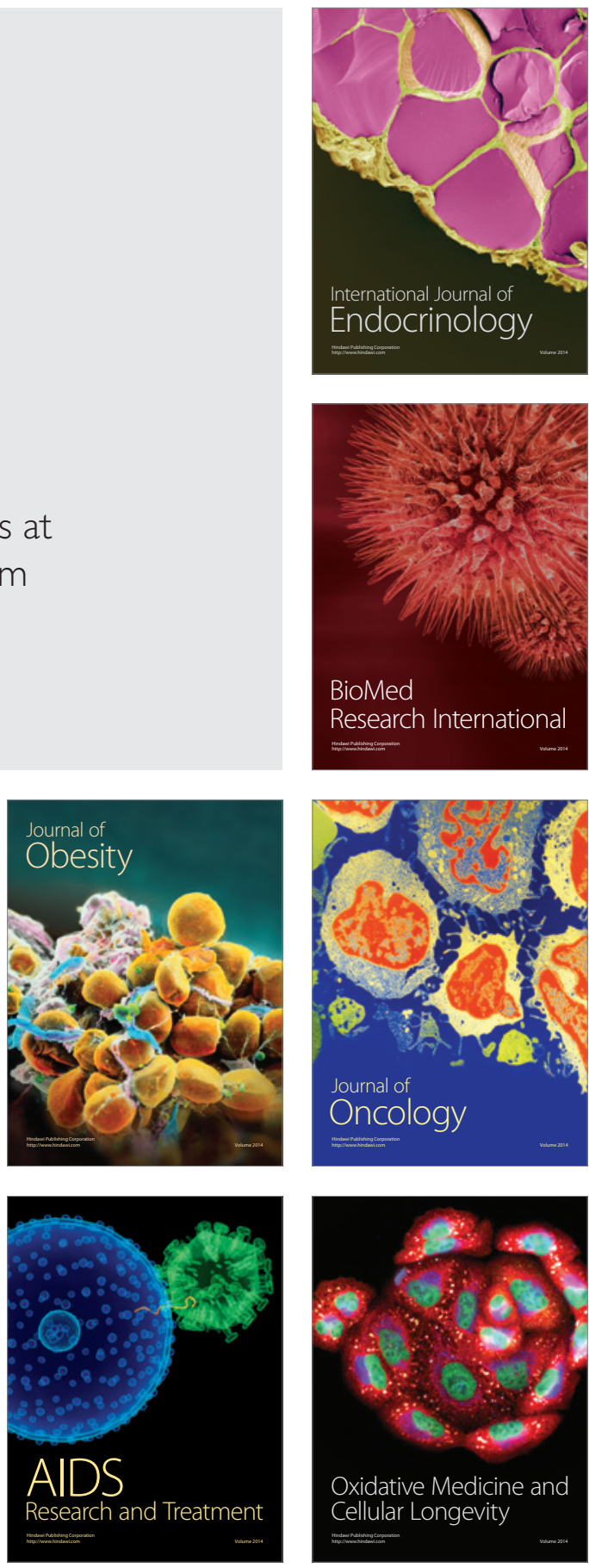